\title{
Review Article \\ Robotic versus Open Thyroidectomy for Differentiated Thyroid Cancer: An Evidence-Based Review
}

\author{
Shirley Yuk Wah Liu and Enders Kwok Wai Ng \\ Department of Surgery, Prince of Wales Hospital, Faculty of Medicine, Chinese University of Hong Kong, New Territories, Hong Kong \\ Correspondence should be addressed to Enders Kwok Wai Ng; endersng@surgery.cuhk.edu.hk
}

Received 28 December 2015; Accepted 17 February 2016

Academic Editor: Thomas J. Fahey

Copyright (C) 2016 S. Y. W. Liu and E. K. W. Ng. This is an open access article distributed under the Creative Commons Attribution License, which permits unrestricted use, distribution, and reproduction in any medium, provided the original work is properly cited.

\begin{abstract}
While open thyroidectomy (OT) is advocated as the gold standard treatment for differentiated thyroid cancer, the contemporary use of robotic thyroidectomy (RT) is often controversial. Although RT combines the unique benefits of the surgical robot and remote access thyroidectomy, its applicability on cancer patients is challenged by the questionable oncological benefits and safety. This review aims to analyze the current literature evidence in comparing RT to OT on thyroid cancers for their perioperative and oncological outcomes. To date, no randomized controlled trial is available in comparing RT to OT. All published studies are nonrandomized or retrospective comparisons. Current data suggests that RT compares less favorably than OT for longer operative time, higher cost, and possibly inferior oncological control with lower number of central lymph nodes retrieved. In terms of morbidity, quality of life outcomes, and short-term recurrence rates, RT and OT are comparable. While conventional OT continues to be appropriate for most thyroid cancers, RT should better be continued by expert surgeons on selected patients who have lowrisk thyroid cancers and have high expectations on cosmetic outcomes. Future research should embark on prospective randomized studies for unbiased comparisons. Long-term follow-up studies are also needed to evaluate outcomes on recurrence and survival.
\end{abstract}

\section{Introduction}

Since the first introduction of endoscopic endocrine neck surgery in 1996 [1, 2], many different techniques of remote access thyroidectomy without a conventional cervical incision have been developed [3, 4]. Although the pursuit on cosmetic superiority can be achieved, remote access thyroidectomy by the endoscopic approach is inevitably associated with the disadvantages of narrow working space, two-dimensional operative view, and restricted instrument manipulation. These have largely limited the applicability of endoscopic thyroidectomy on thyroid neoplasia. Until early 2000s when the Da Vinci robotic system (Intuitive Surgical, Inc., Sunnyvale, CA, USA) was launched, many minimally invasive thyroid surgeons have shifted their enthusiasm towards robotic thyroid surgery [5-10]. The robotic surgical system provides surgeons with the benefits of improved surgical dexterity by multiarticulated instrumentation, stable operative view by hand-tremor filtration technology, and excellent visualization by three-dimensional magnification. These have remarkably extended the indications of the technique onto differentiated thyroid cancers.

Despite the vast abundance of literature reports supporting the safety and effectiveness of robotic thyroidectomy (RT) [11-18], many thyroid surgeons are not convinced on the merits of the procedure in treating thyroid cancers. Substantial controversies over the role of RT have emerged with respect to its safety, perioperative outcomes, and oncological completeness. In October 2011, the Food and Drug Administration had revoked approval for the use of the robot in thyroid surgery in the United States. While excellent outcomes can be confidently achieved by conventional open thyroidectomy (OT) in thyroid cancers, many surgeons who used to be advocates of the robot had stopped practicing RT due to its off-label usage, higher costs, steep learning curve, and unclear patient benefits [19-21]. In this review, we aim to analyze the current literature evidence in comparing RT to OT for the management of differentiated thyroid cancers. 


\section{Robotic Thyroidectomy for Thyroid Cancer}

There are three most commonly described RT approaches for thyroid cancers. They are gasless transaxillary approach (TA), bilateral axillobreast approach (BABA), and gasless unilateral axillobreast approach (GUAB). At present, RT is almost exclusively applied on differentiated thyroid cancers (DTC) alone [22-49]. Most reports have no gender restriction but many centers limit their surgery to adults younger than 55 to 70 years $[27,39,45,47]$. The size limit is commonly set at $\leq 2-4 \mathrm{~cm}$ for low-risk DTC and $\leq 5 \mathrm{~cm}$ for benign or indeterminate nodules [22-49]. RT is not technically feasible for every patient. In terms of disease factor, locally advanced tumors with extrathyroidal invasion to larynx, trachea, esophagus, or recurrent laryngeal nerves, distant metastases, and posteriorly located tumors are considered unsuitable for RT. Minimal anterior strap muscle invasion is often not regarded as a contraindication because en bloc resection of strap muscles can be safely achieved by the robot [26, 29-31]. Presence of multiple metastatic lymph nodes at lateral compartment is no longer a contraindication because concomitant robotic modified radical neck dissection (MRND) can be performed [22, 26, 31]. As for patient factor, prior surgery or irradiation at the neck, breast (for BABA or GUAB), and axilla (for TA or GUAB) are absolute contraindications. Obesity and thyroiditis are relative contraindications in the North American population as a result of perceived operative difficulties [33, 40].

In the literature, more than 25 studies had been published comparing the outcomes between RT and OT for differentiated thyroid cancers [22-49]. Except for three American studies [33, 40, 43], almost all reports are originated from South Korea which represents the main body of worldwide experiences and literature evidences. To date, no randomized controlled trial is available in comparing RT to OT. All available studies are nonrandomized or retrospective comparisons that are subjected to selection biases. In addition to five metaanalyses comparing the outcomes between RT and OT in general [11-15], three more meta-analyses had specifically summarized the differences between RT and OT for thyroid cancer [16-18]. These literature evidences are to be discussed here with respect to the comparisons on the perioperative and oncological outcomes.

\subsection{Perioperative Outcomes}

2.1.1. Operative Time. As consistently shown in 19 comparative studies [22-35, 38, 40, 41, 43-47] and 7 meta-analyses [11-17] comparing RT to OT, the operative time of RT was significantly longer than that of OT for pooled mean differences of 39-54 minutes irrespective of the operative approaches. Although the operative time of RT could be reduced with accumulation of experiences, it was hardly possible for RT to achieve comparable operative time with that of OT [50-52]. This was mainly attributed to the need of extra time for skin flap dissection and robotic docking.

2.1.2. Hospital Stay. The length of hospital stay was analyzed in 15 comparative studies [22-34, 40, 41] and 4 meta-analyses
[13-16]. Except for three studies [26, 30, 33], all available data did not find a significant difference between RT and OT for the length of hospital stay.

2.1.3. Postoperative Pain. In addition to pain in the neck, pain at remote wound sites and skin flaps are inherently associated with RT. Using different assessment scales, postoperative pain had been compared in 8 studies [22-24, 27, 28, 40, $44,48]$. Except for two studies reporting significantly less pain in RT than in OT on the first two postoperative days $[23,44]$, no difference was observed between RT and OT for postoperative pain scores [27, 40, 48] and analgesic requirement $[23,27,40]$ in all studies. Chronic pain after $3-$ 6 months was also similar between the two procedures [22, $24,28]$. Due to the adoption of different measurement scales, meta-analytical comparison of postoperative pain from these studies was difficult. Overall evidence suggested that RT and OT were comparable for postoperative pain.

2.1.4. Recurrent Laryngeal Nerve Injury. In the literature, there was no universal consensus in defining transient and permanent recurrent laryngeal nerve (RLN) injuries. Their quoted incidences in RT varied between $1-7 \%$ for transient injury and $0-2 \%$ for permanent injury (Table 1). Despite the discrepancies in their definitions, no significant difference was observed between RT and OT for the rates of transient and permanent RLN injuries in 18 studies [22-39]. Except for one meta-analysis by Lang et al. [11], all 6 available metaanalyses consistently found no difference between RT and OT for the rates of transient and permanent RLN injuries [1217]. The current evidence still supported that the risk of RLN injuries was not increased by RT.

2.1.5. Hypoparathyroidism. The definitions of postoperative transient and permanent hypoparathyroidism also varied among different studies (Table 2). The reported rates of transient and permanent hypoparathyroidism in RT ranged from $0-53 \%$ and $0-3 \%$, respectively. In 18 studies comparing RT to OT, all except three studies $[24,30,38]$ reported no significant difference between the two groups for the rates of transient hypoparathyroidism while the rates of permanent hypoparathyroidism were comparable among all studies [2238, 40]. Despite the slight variation in the definitions, all available meta-analyses consistently showed that the rates of permanent hypoparathyroidism were comparable between RT and OT [11-17]. As for transient hypoparathyroidism, except for the studies by Jackson et al. and Kandil et al. [12, 15], the pooled results from all other meta-analyses revealed no significant difference between RT and OT [11, 13, 14, 16, 17]. Hence, the current evidence also supported that the risk of hypoparathyroidism was not increased by RT.

2.1.6. Bleeding and Hematoma. Although bleeding and hematoma are the major lethal complications of thyroidectomy, the reported incidences in RT remained below 2-3\% and were comparable with those of OT in 16 studies [22$33,35,37,38,40]$. As reflected by 6 meta-analyses, the rates 


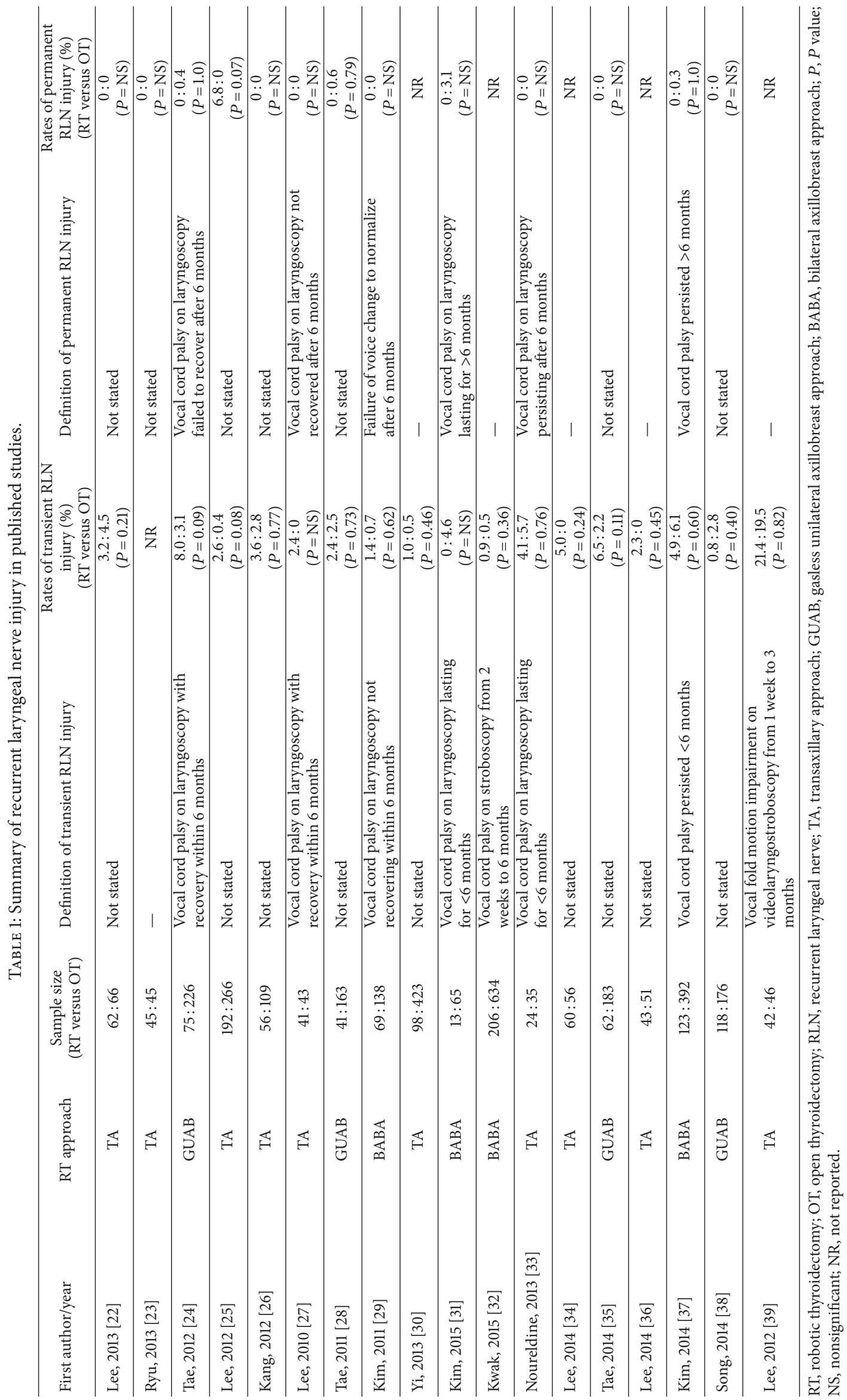




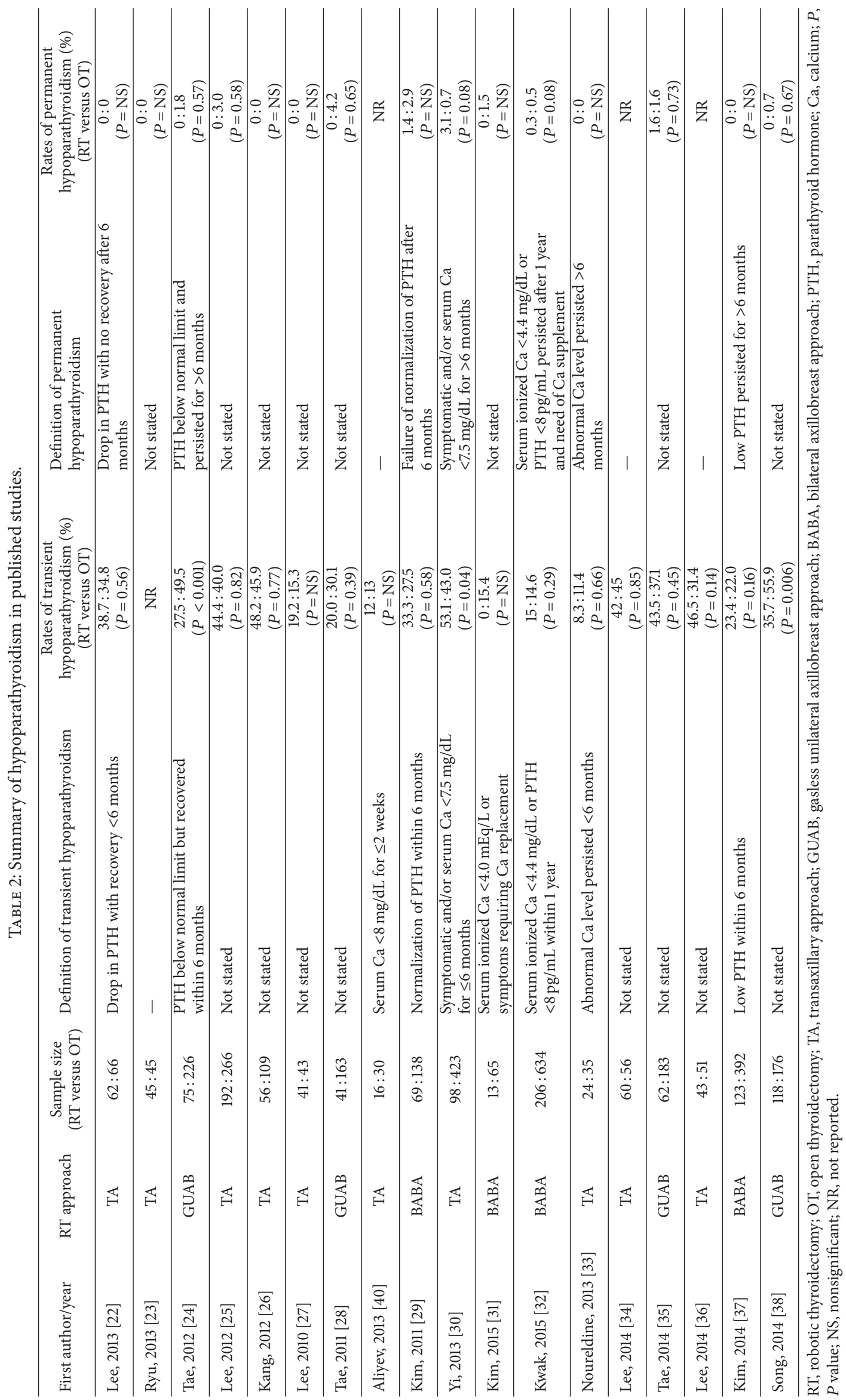


of bleeding and hematoma were similar between RT and OT $[11-15,17]$.

2.1.7. Other Complications. According to the results from the latest meta-analyses, the outcomes of RT and OT were comparable for the rates of seroma formation [12-15, 17], chyle leak [12-17], and tracheal injury [15]. One study also reported a significantly lower degree of postoperative nausea and vomiting in RT [44]. Wound infection rates were similar between RT and OT in 3 other studies [22, 23, 29].

2.1.8. Voice Dysfunction. Postoperative voice change independent of RLN injury had been compared in 5 studies [22, $27,39,45,47]$. Using subjective symptom questionnaires, Tae et al. found that the subjective postoperative voice functions at 1 day, 1 month, and 3 months were significantly better in RT (GUAB) than in OT [45]. When they extended their study duration to 2-year follow-up, RT was found to have advantages of better recovery of voice symptoms and acoustic parameters over OT [47]. In three other studies using TA in RT [22, 27, 39], subjective and objective voice dysfunctions were contrarily found to be comparable between RT and OT. More prospective studies are needed before convincing conclusion can be drawn on the differences in voice dysfunction between RT and OT.

2.1.9. Swallowing Dysfunction. In three studies evaluating the subjective swallowing dysfunction, RT was shown to have significantly less dysfunction than OT in two studies [22, 27] but was similar to OT in another study [45]. More prospective evidence is needed to truly compare such outcome between the two procedures.

2.1.10. Sensory Change. Due to more extensive skin flap dissection, chest paresthesia was significantly more common after RT than OT in both TA and BABA techniques [22, $27,38]$. In a prospective study by Kim et al, anterior chest paresthesia after BABA thyroidectomy was found to be completely normalized by 3 months [53]. While Lee et al. reported significantly more neck paresthesia in OT than in RT using TA $[22,27]$, Song et al. found no such difference in OT and RT using BABA [38].

2.1.11. Cosmetic Satisfaction. Cosmetic superiority was considered to be the most concerned advantage of RT. In all 6 studies comparing cosmetic satisfaction between RT and OT at different time-points from postoperative 1 day to 6 months, RT was associated with significantly higher cosmetic satisfaction scores irrespective of the operative approaches $[22,24,27,28,32,34]$. In a prospective study evaluating the postoperative body image by Lee et al, significantly better self-body image scores were found in RT than in OT from postoperative 3 months till 9 months [34]. In another study analyzing the postoperative cosmetic concerns by Koo do et al., the degree of scarring and psychological distress were also significantly better after RT than OT [48]. Hence, the cosmetic benefits of RT were confirmed by the current literature evidences.
2.1.12. Cost. One of the greatest disadvantages of RT is cost. Based on a cost model consisting of operating room charges, anesthesia fee, consumable cost, equipment depreciation, and maintenance cost, Cabot et al. found that RT was 1.5 times more expensive than OT (USD $13670 \pm 1384$ versus $9028 \pm$ 891, $P<$ 0.001) [54]. Even when the annual case load was increased to reduce the equipment depreciation cost per case, such cost difference between RT and OT could hardly be resolved. In another study analyzing the relative costs, Broome et al. also found that the cost of RT was 2.1 times higher than that of OT (USD 5797 versus 2668) [55]. In two recent comparative studies on thyroid cancer, the cost of RT was again shown to be significantly higher than that of OT $[31,32]$.

\subsection{Oncological Outcomes}

2.2.1. Lymph Node Retrieval. Radical central compartment nodal dissection (CCD) often represents the hallmark of favorable oncological control. In 15 studies comparing the number of LN retrieved during CCD [22-32, 35-37, 41], 6 reported a significantly lower number of $\mathrm{LN}$ retrieved in RT than in OT but 9 other studies found comparable results between the two procedures (Table 3). In three meta-analyses, the number of central LN retrieved was consistently lower in RT than in OT though the reported absolute differences were small (number <1) [16-18]. As for the number of LN retrieved during MRND for more advanced disease stages, only three studies compared RT to OT and no significant difference was found $[22,26,31]$. Based on the evidence from pooled analyses, RT might be inferior to OT in terms of the number of central LN retrieved.

2.2.2. Surgical Completeness of Resection. In thyroid cancer, surgical completeness of resection is commonly estimated by the serum thyroglobulin (Tg) levels and the RAI uptake levels on posttherapy whole-body scan (RxWBS) at radioiodine (RAI) ablation. The thyrotropin- (TSH-) stimulated Tg (sTg) level is a reliable surrogate marker for the amount of remnant thyroid tissue after total thyroidectomy. It is measured upon TSH stimulation by either thyroid hormone withdrawal or human recombinant TSH stimulation. Ablation sTg is measured at the time of RAI ablation while control sTg is measured at 6-12 months after RAI. In the literature, ablation sTg levels were reported to be significantly higher in RT than in OT in 4 studies $[24,30,34,35]$ but were similar between the two groups in 5 other studies [29, 31, 36, 37, 42]. Although two meta-analyses by Wang et al. and Son et al. found no difference between RT and OT for sTg levels [16, 17], another meta-analysis consisting of the highest number of individual studies $(n=6)$ by Lang et al. contrarily revealed a significantly higher sTg level in RT than in OT [18]. As for control sTg, its levels were compared in three studies and no significant difference was observed between RT and OT $[24,30,35]$. Overall evidence suggested that the amount of remnant thyroid tissue (as reflected by ablation sTg levels) might be higher in RT than in OT but such difference was resolved after RAI ablation. Using abnormal RAI uptake at 
TABLE 3: Summary of oncological outcomes in published studies.

\begin{tabular}{|c|c|c|c|c|}
\hline First author/year & RT approach & $\begin{array}{c}\text { Sample size } \\
\text { (RT versus } \\
\text { OT) }\end{array}$ & $\begin{array}{c}\text { Mean number of } \\
\text { central LN retrieved } \\
\text { (RT versus OT) }\end{array}$ & $\begin{array}{l}\text { Mean ablation } \\
\text { sTg }(\mathrm{ng} / \mathrm{mL}) \\
(\mathrm{RT} \text { versus OT) }\end{array}$ \\
\hline Lee, 2013 [22] & $\mathrm{TA}$ & $62: 66$ & $\begin{array}{c}8.1: 7.9 \\
(P=0.21)\end{array}$ & NR \\
\hline Ryu, 2013 [23] & $\mathrm{TA}$ & $45: 45$ & $\begin{array}{c}5.7: 7.0 \\
(P=0.23)\end{array}$ & NR \\
\hline Tae, 2012 [24] & GUAB & $75: 226$ & $\begin{array}{c}4.4: 7.7 \\
(P<0.001)\end{array}$ & $\begin{array}{c}12.7: 4.9 \\
(P=0.03)\end{array}$ \\
\hline Lee, 2012 [25] & $\mathrm{TA}$ & $192: 266$ & $\begin{array}{c}4.6: 5.7 \\
(P=0.004) \\
\end{array}$ & NR \\
\hline Kang, 2012 [26] & $\mathrm{TA}$ & $56: 109$ & $\begin{array}{c}6.5: 8.6 \\
(P=0.03) \\
\end{array}$ & NR \\
\hline Lee, 2010 [27] & $\mathrm{TA}$ & $41: 43$ & $\begin{array}{c}4.4: 4.3 \\
(P=0.84)\end{array}$ & NR \\
\hline Tae, 2011 [28] & GUAB & $41: 163$ & $\begin{array}{c}4.7: 9.6 \\
(P<0.01)\end{array}$ & NR \\
\hline Kim, 2011 [29] & BABA & $69: 138$ & $\begin{array}{c}4.7: 4.8 \\
(P=0.80)\end{array}$ & $\begin{array}{c}0.8: 0.8 \\
(P=0.97)\end{array}$ \\
\hline $\mathrm{Yi}, 2013$ [30] & TA & $98: 423$ & $\begin{array}{l}6.5: 7.0^{\wedge} \\
(P=0.57)\end{array}$ & $\begin{array}{c}26 \%: 10.6 \%^{*} \\
(P=0.001)\end{array}$ \\
\hline Kim, 2015 [31] & BABA & $13: 65$ & $\begin{array}{l}12.8: 12.7 \\
(P=0.97)\end{array}$ & $\begin{array}{c}2.5: 2.8 \\
(P=\mathrm{NS})\end{array}$ \\
\hline Kwak, 2015 [32] & BABA & $206: 634$ & $\begin{array}{c}5.8: 8.4 \\
(P=0.001)\end{array}$ & NR \\
\hline Lee, 2014 [34] & TA & $60: 56$ & NR & $\begin{array}{c}5.3: 1.6 \\
(P=0.005)\end{array}$ \\
\hline Tae, 2014 [35] & GUAB & $62: 183$ & $\begin{array}{c}4.1: 5.4 \\
(P=0.24)\end{array}$ & $\begin{array}{c}10.2: 3.8 \\
(P<0.001)\end{array}$ \\
\hline Lee, 2014 [36] & $\mathrm{TA}$ & $43: 51$ & $\begin{array}{c}4.9: 6.3 \\
(P=0.06)\end{array}$ & $\begin{array}{c}4.4: 4.1 \\
(P=0.67)\end{array}$ \\
\hline Kim, 2014 [37] & BABA & $123: 392$ & $\begin{array}{c}8.7: 10.4 \\
(P=0.006)\end{array}$ & $\begin{array}{c}1.3: 1.1 \\
(P=0.65)\end{array}$ \\
\hline Lee, 2015 [41] & $\mathrm{TA}$ & $206: 206$ & $\begin{array}{c}5.8: 6.6 \\
(P=0.10)\end{array}$ & NR \\
\hline Lee, 2011 [42] & BABA & $174: 237$ & NR & $\begin{array}{c}1.4: 1.2 \\
(P=0.99)\end{array}$ \\
\hline
\end{tabular}

RT, robotic thyroidectomy; OT, open thyroidectomy; LN, lymph nodes; sTg, thyrotropin-stimulated serum thyroglobulin; TA, transaxillary approach; GUAB, gasless unilateral axillobreast approach; BABA, bilateral axillobreast approach; $P, P$ value; NS, nonsignificant; NR, not reported. ${ }^{\wedge}$ Median (range). ${ }^{*}$ Percentage of patients with abnormal ablation sTg (level $>2 \mathrm{ng} / \mathrm{mL})$.

RxWBS to represent the amount of remnant thyroid tissues, 6 studies reported comparable results between RT and OT [25, $26,34,35,40,42]$ but one study found a significantly higher result in RT [36]. The available evidence was considered inadequate for drawing a definite conclusion on the surgical completeness of resection by the two procedures.

2.2.3. Tumor Recurrence. Short-term locoregional recurrence within the first two postoperative years was comparable between RT and OT in 7 studies [22-26, 35, 40]. In the only long-term follow-up study by Lee et al, the rates of locoregional recurrence at 5 years were similar between RT and OT (1.2\% versus $1.2 \%)$ [41].
2.2.4. Survival Outcomes. In the literature, the survival outcomes between RT and OT were only compared in one study [41]. At 5-year follow-up, Lee et al. observed no significant difference between RT and OT for the disease-free survival (99.7\% versus $98.7 \%, P=0.89$ ). Longer time is needed to wait for more long-term follow-up data before comparison on survival outcomes can be made.

2.3. Generalizability of Evidence. As stated before, almost all the available evidences about the use of RT on thyroid cancer were originated from South Korea. The generalizability of these results to the North American or European populations is questionable because of the differences in body habitus, 
incidence of subcentimeter nodules, prevalence of obesity, and occurrence of thyroiditis in different ethnic groups [10].

\section{Conclusion}

Despite the established advantages on cosmesis, current data suggests that RT compares less favorably than OT for longer operative time, higher cost, and possibly inferior oncological control with lower number of central LN retrieved. In terms of morbidity and quality of life outcomes, RT and OT are comparable for thyroid cancer patients. While conventional OT continues to be appropriate for most thyroid cancer patients, RT should better be continued by expert surgeons on selected patients who have low-risk thyroid cancers and have high expectations on cosmetic outcomes. More prospective long-term follow-up studies are needed to define the oncological safety of RT.

\section{Conflict of Interests}

All authors declare that there is no conflict of interests regarding the publication of this paper.

\section{References}

[1] M. Gagner, "Endoscopic subtotal parathyroidectomy in patients with primary hyperparathyroidism," British Journal of Surgery, vol. 83 , no. 6 , p. $875,1996$.

[2] C. S. Hüscher, S. Chiodini, C. Napolitano, and A. Recher, "Endoscopic right thyroid lobectomy," Surgical Endoscopy, vol. 11, no. 8, article 877, 1997.

[3] B. H. Lang, "Minimally invasive thyroid and parathyroid operations: surgical techniques and pearls," Advances in Surgery, vol. 44, no. 1, pp. 185-198, 2010.

[4] D. Linos, "Minimally invasive thyroidectomy: a comprehensive appraisal of existing techniques," Surgery, vol. 150, no. 1, pp. 1724, 2011.

[5] N. Tanna, A. S. Joshi, R. S. Glade, D. Zalkind, and N. Sadeghi, "Da Vinci robot-assisted endocrine surgery: novel applications in otolaryngology," Otolaryngology-Head and Neck Surgery, vol. 135, no. 4, pp. 633-635, 2006.

[6] K. E. Lee, E. Kim, D. H. Koo, J. Y. Choi, K. H. Kim, and Y.-K. Youn, "Robotic thyroidectomy by bilateral axillo-breast approach: review of 1026 cases and surgical completeness," Surgical Endoscopy, vol. 27, no. 8, pp. 2955-2962, 2013.

[7] E. J. Ban, J. Y. Yoo, W. W. Kim et al., "Surgical complications after robotic thyroidectomy for thyroid carcinoma: a single center experience with 3,000 patients," Surgical Endoscopy, vol. 28, no. 9, pp. 2555-2563, 2014.

[8] H. K. Byeon, D. H. Kim, J. W. Chang et al., "Comprehensive application of robotic retroauricular thyroidectomy: the evolution of robotic thyroidectomy," The Laryngoscope, 2015.

[9] D. S. Bae, D. H. Koo, J. Y. Choi, E. Kim, K. E. Lee, and Y.-K. Youn, "Current status of robotic thyroid surgery in South Korea: a web-based survey," World Journal of Surgery, vol. 38, no. 10, pp. 2632-2639, 2014.

[10] A. M. Hinson, E. Kandil, S. O’Brien et al., "Trends in robotic thyroid surgery in the United States from 2009 through 2013," Thyroid, vol. 25, no. 8, pp. 919-926, 2015.

[11] B. H.-H. Lang, C. K. H. Wong, J. S. Tsang, K. P. Wong, and K. Y. Wan, "A systematic review and meta-analysis comparing surgically-related complications between robotic-assisted thyroidectomy and conventional open thyroidectomy," Annals of Surgical Oncology, vol. 21, no. 3, pp. 850-861, 2014.

[12] N. R. Jackson, L. Yao, R. P. Tufano, and E. H. Kandil, "Safety of robotic thyroidectomy approaches: meta-analysis and systematic review," Head and Neck, vol. 36, no. 1, pp. 137-143, 2014.

[13] G. H. Sun, L. Peress, and M. A. Pynnonen, "Systematic review and meta-analysis of robotic vs conventional thyroidectomy approaches for thyroid disease," Otolaryngology-Head and Neck Surgery, vol. 150, no. 4, pp. 520-532, 2014.

[14] H. Shen, C. Shan, and M. Qiu, "Systematic review and metaanalysis of transaxillary robotic thyroidectomy versus open thyroidectomy," Surgical Laparoscopy, Endoscopy and Percutaneous Techniques, vol. 24, no. 3, pp. 199-206, 2014.

[15] E. Kandil, A. Y. Hammad, R. R. Walvekar et al., "Robotic thyroidectomy versus nonrobotic approaches: a meta-analysis examining surgical outcomes," Surgical Innovation, 2015.

[16] Y. C. Wang, K. Liu, J. J. Xiong, and J. Q. Zhu, "Robotic thyroidectomy versus conventional open thyroidectomy for differentiated thyroid cancer: meta-analysis," Journal of Laryngology \& Otology, vol. 129, no. 6, pp. 558-567, 2015.

[17] S. K. Son, J. H. Kim, J. S. Bae, and S. H. Lee, "Surgical safety and oncologic effectiveness in robotic versus conventional open thyroidectomy in thyroid cancer: a systematic review and metaanalysis," Annals of Surgical Oncology, vol. 22, no. 9, pp. 30223032, 2015.

[18] B. H.-H. Lang, C. K. H. Wong, J. S. Tsang, K. P. Wong, and K. Y. Wan, "A systematic review and meta-analysis evaluating completeness and outcomes of robotic thyroidectomy," Laryngoscope, vol. 125, no. 2, pp. 509-518, 2015.

[19] N. D. Perrier, "Why I have abandoned robot-assisted transaxillary thyroid surgery," Surgery, vol. 152, no. 6, pp. 1025-1026, 2012.

[20] W. B. Inabnet III, "Robotic thyroidectomy: must we drive a luxury sedan to arrive at our destination safely?" Thyroid, vol. 22, no. 10, pp. 988-990, 2012.

[21] D. Linos, "Less is more. The example of minimally invasive thyroidectomy," JAMA Surgery, vol. 148, no. 9, pp. 808-809, 2013.

[22] J. Lee, I. S. Kwon, E. H. Bae, and W. Y. Chung, "Comparative analysis of oncological outcomes and quality of life after robotic versus conventional open thyroidectomy with modified radical neck dissection in patients with papillary thyroid carcinoma and lateral neck node metastases," Journal of Clinical Endocrinology and Metabolism, vol. 98, no. 7, pp. 2701-2708, 2013.

[23] H. R. Ryu, J. Lee, J.-H. Park et al., "A comparison of postoperative pain after conventional open thyroidectomy and transaxillary single-incision robotic thyroidectomy: a prospective study," Annals of Surgical Oncology, vol. 20, no. 7, pp. 2279-2284, 2013.

[24] K. Tae, Y. B. Ji, S. H. Cho, S. H. Lee, D. S. Kim, and T. W. Kim, "Early surgical outcomes of robotic thyroidectomy by a gasless unilateral axillo-breast or axillary approach for papillary thyroid carcinoma: 2 years' experience," Head and Neck, vol. 34, no. 5, pp. 617-625, 2012.

[25] S. Lee, H. R. Ryu, J. H. Park et al., "Early surgical outcomes comparison between robotic and conventional open thyroid surgery for papillary thyroid microcarcinoma," Surgery, vol. 151, no. 5, pp. 724-730, 2012.

[26] S.-W. Kang, S. H. Lee, J. H. Park et al., "A comparative study of the surgical outcomes of robotic and conventional open modified radical neck dissection for papillary thyroid carcinoma with 
lateral neck node metastasis," Surgical Endoscopy and Other Interventional Techniques, vol. 26, no. 11, pp. 3251-3257, 2012.

[27] J. Lee, K. Y. Nah, R. M. Kim, Y. H. Ahn, E.-Y. Soh, and W. Y. Chung, "Differences in postoperative outcomes, function, and cosmesis: open versus robotic thyroidectomy," Surgical Endoscopy, vol. 24, no. 12, pp. 3186-3194, 2010.

[28] K. Tae, Y. B. Ji, J. H. Jeong, S. H. Lee, M. A. Jeong, and C. W. Park, "Robotic thyroidectomy by a gasless unilateral axillo-breast or axillary approach: our early experiences," Surgical Endoscopy, vol. 25, no. 1, pp. 221-228, 2011.

[29] W. W. Kim, J. S. Kim, S. M. Hur et al., "Is robotic surgery superior to endoscopic and open surgeries in thyroid cancer?" World Journal of Surgery, vol. 35, no. 4, pp. 779-784, 2011.

[30] O. Yi, J. H. Yoon, Y.-M. Lee et al., “Technical and oncologic safety of robotic thyroid surgery," Annals of Surgical Oncology, vol. 20, no. 6, pp. 1927-1933, 2013.

[31] B. S. Kim, K. H. Kang, and S. J. Park, "Robotic modified radical neck dissection by bilateral axillary breast approach for papillary thyroid carcinoma with lateral neck metastasis," Head and Neck, vol. 37, no. 1, pp. 37-45, 2015.

[32] H. Y. Kwak, H. Y. Kim, H. Y. Lee et al., "Robotic thyroidectomy using bilateral axillo-breast approach: comparison of surgical results with open conventional thyroidectomy," Journal of Surgical Oncology, vol. 111, no. 2, pp. 141-145, 2015.

[33] S. I. Noureldine, N. R. Jackson, R. P. Tufano, and E. Kandil, "A comparative North American experience of robotic thyroidectomy in a thyroid cancer population," Langenbeck's Archives of Surgery, vol. 398, no. 8, pp. 1069-1074, 2013.

[34] S. Lee, H. Y. Kim, C. R. Lee et al., "A prospective comparison of patient body image after robotic thyroidectomy and conventional open thyroidectomy in patients with papillary thyroid carcinoma," Surgery, vol. 156, no. 1, pp. 117-125, 2014.

[35] K. Tae, C. M. Song, Y. B. Ji, K. R. Kim, J. Y. Kim, and Y. Y. Choi, "Comparison of surgical completeness between robotic total thyroidectomy versus open thyroidectomy," Laryngoscope, vol. 124, no. 4, pp. 1042-1047, 2014.

[36] S. Lee, C. R. Lee, S. C. Lee et al., "Surgical completeness of robotic thyroidectomy: a prospective comparison with conventional open thyroidectomy in papillary thyroid carcinoma patients," Surgical Endoscopy, vol. 28, no. 4, pp. 1068-1075, 2014.

[37] B. S. Kim, K. H. Kang, H. Kang, and S. J. Park, "Central neck dissection using a bilateral axillo-breast approach for robotic thyroidectomy: comparison with conventional open procedure after propensity score matching," Surgical Laparoscopy, Endoscopy \& Percutaneous Techniques, vol. 24, no. 1, pp. 67-72, 2014.

[38] C. M. Song, Y. B. Ji, H. S. Bang, C. W. Park, H. Kim, and K. Tae, "Long-term sensory disturbance and discomfort after robotic thyroidectomy," World Journal of Surgery, vol. 38, no. 7, pp. 17431748, 2014.

[39] J. Lee, K. Y. Na, R. M. Kim et al., "Postoperative functional voice changes after conventional open or robotic thyroidectomy: a prospective trial," Annals of Surgical Oncology, vol. 19, no. 9, pp. 2963-2970, 2012.

[40] S. Aliyev, H. E. Taskin, O. Agcaoglu et al., "Robotic transaxillary total thyroidectomy through a single axillary incision," Surgery, vol. 153, no. 5, pp. 705-710, 2013.

[41] S. G. Lee, J. Lee, M. J. Kim et al., "Long-term oncologic outcome of robotic versus open total thyroidectomy in PTC: a casematched retrospective study," Surgical Endoscopy, 2015.
[42] K. E. Lee, D. H. Koo, H. J. Im et al., "Surgical completeness of bilateral axillo-breast approach robotic thyroidectomy: comparison with conventional open thyroidectomy after propensity score matching," Surgery, vol. 150, no. 6, pp. 1266-1274, 2011.

[43] M. Abdelgadir Adam, P. Speicher, J. Pura et al., "Robotic thyroidectomy for cancer in the US: patterns of use and shortterm outcomes," Annals of Surgical Oncology, vol. 21, no. 12, pp. 3859-3864, 2014.

[44] J. Y. Yoo, Y. J. Chae, H. B. Cho, K. H. Park, J. S. Kim, and S. Y. Lee, "Comparison of the incidence of postoperative nausea and vomiting between women undergoing open or robot-assisted thyroidectomy," Surgical Endoscopy and Other Interventional Techniques, vol. 27, no. 4, pp. 1321-1325, 2013.

[45] K. Tae, K. Y. Kim, B. R. Yun et al., "Functional voice and swallowing outcomes after robotic thyroidectomy by a gasless unilateral axillo-breast approach: comparison with open thyroidectomy," Surgical Endoscopy and Other Interventional Techniques, vol. 26, no. 7, pp. 1871-1877, 2012.

[46] J.-A. Kim, J.-S. Kim, M.-S. Chang, Y.-K. Yoo, and D.-K. Kim, "Influence of carbon dioxide insufflation of the neck on intraocular pressure during robot-assisted endoscopic thyroidectomy: a comparison with open thyroidectomy," Surgical Endoscopy, vol. 27, no. 5, pp. 1587-1593, 2013.

[47] C. M. Song, B. R. Yun, Y. B. Ji, E. S. Sung, K. R. Kim, and K. Tae, "Long-term voice outcomes after robotic thyroidectomy," World Journal of Surgery, vol. 40, no. 1, pp. 110-116, 2016.

[48] H. Koo do, M. Kim da, J. Y. Choi, K. E. Lee, S. H. Cho, and Y. K. Youn, "In-depth survey of scarring and distress in patients undergoing bilateral axillo-breast approach robotic thyroidectomy or conventional open thyroidectomy," Surgical Laparoscopy, Endoscopy \& Percutaneous Techniques, vol. 25, no. 5, pp. 436-439, 2015.

[49] Y. B. Ji, C. M. Song, H. S. Bang, S. H. Lee, Y. S. Park, and K. Tae, "Long-term cosmetic outcomes after robotic/endoscopic thyroidectomy by a gasless unilateral axillo-breast or axillary approach," Journal of Laparoendoscopic and Advanced Surgical Techniques, vol. 24, no. 4, pp. 248-253, 2014.

[50] W. W. Kim, J. H. Jung, and H. Y. Park, “The learning curve for robotic thyroidectomy using a bilateral axillo-breast approach from the 100 cases," Surgical Laparoscopy, Endoscopy \& Percutaneous Techniques, vol. 25, no. 5, pp. 412-416, 2015.

[51] J. H. Park, J. Lee, N. A. Hakim et al., "Robotic thyroidectomy learning curve for beginning surgeons with little or no experience of endoscopic surgery," Head \& Neck, vol. 37, no. 12, pp. 1705-1711, 2015.

[52] J. Lee, J. H. Yun, K. H. Nam, E.-Y. Soh, and W. Y. Chung, “The learning curve for robotic thyroidectomy: a multicenter study," Annals of Surgical Oncology, vol. 18, no. 1, pp. 226-232, 2011.

[53] S.-J. Kim, K. E. Lee, J. P. Myong, D. H. Koo, J. Lee, and Y.-K. Youn, "Prospective study of sensation in anterior chest areas before and after a bilateral axillo-breast approach for endoscopic/robotic thyroid surgery," World Journal of Surgery, vol. 37, no. 5, pp. 1147-1153, 2013.

[54] J. C. Cabot, C. R. Lee, L. Brunaud et al., "Robotic and endoscopic transaxillary thyroidectomies may be cost prohibitive when compared to standard cervical thyroidectomy: a cost analysis," Surgery, vol. 152, no. 6, pp. 1016-1024, 2012.

[55] J. T. Broome, S. Pomeroy, and C. C. Solorzano, "Expense of robotic thyroidectomy: a cost analysis at a single institution," Archives of Surgery, vol. 147, no. 12, pp. 1102-1106, 2012. 


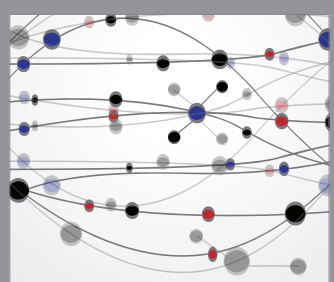

The Scientific World Journal
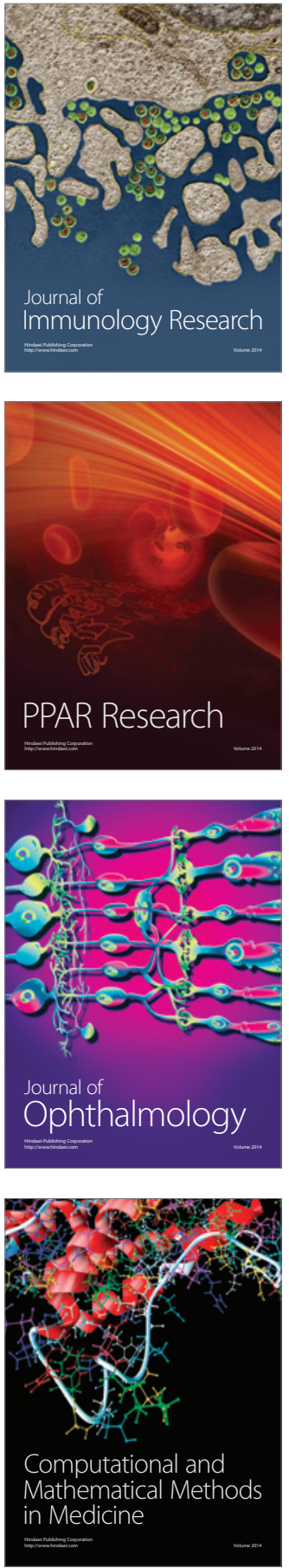

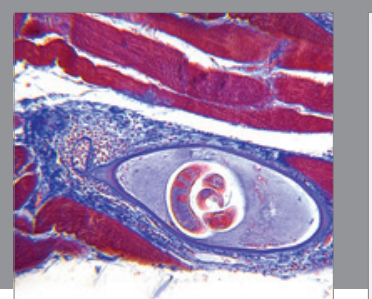

Gastroenterology Research and Practice

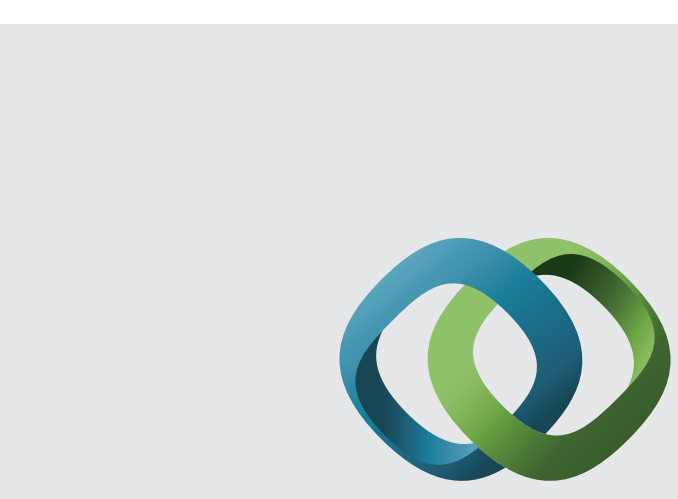

\section{Hindawi}

Submit your manuscripts at

http://www.hindawi.com
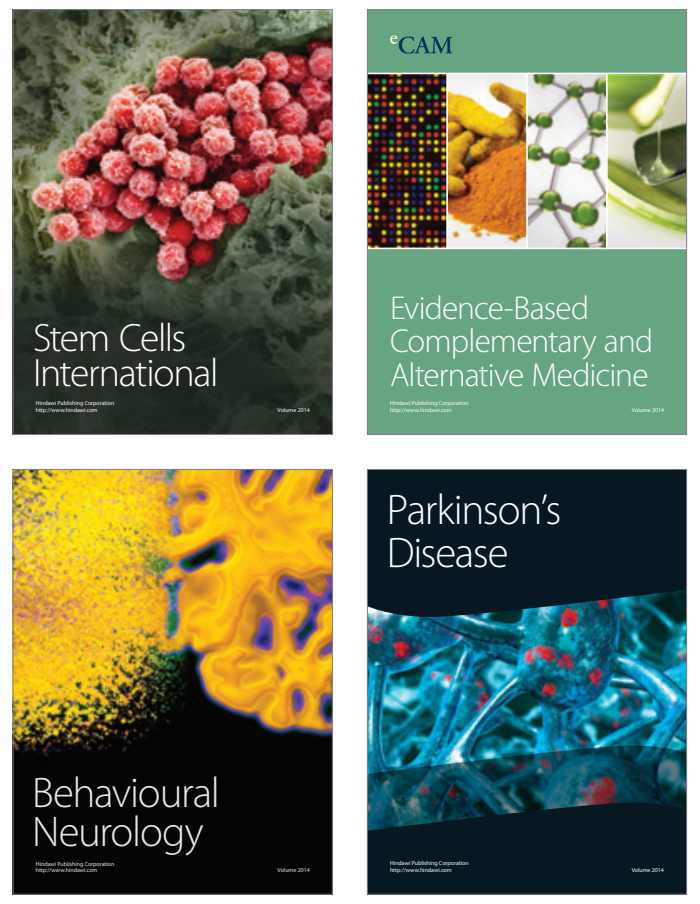
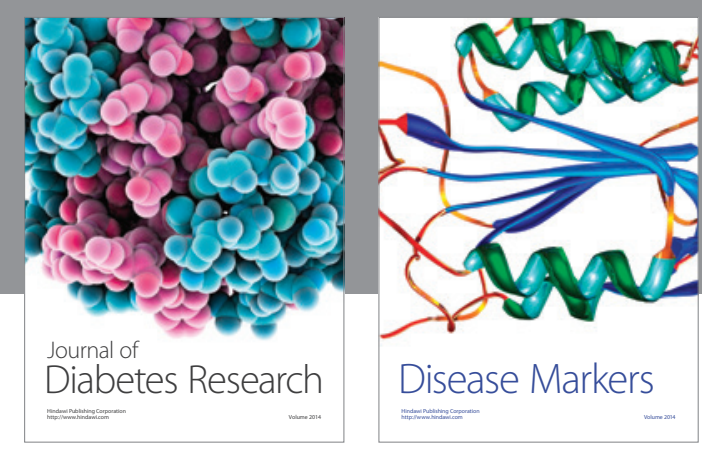

Disease Markers
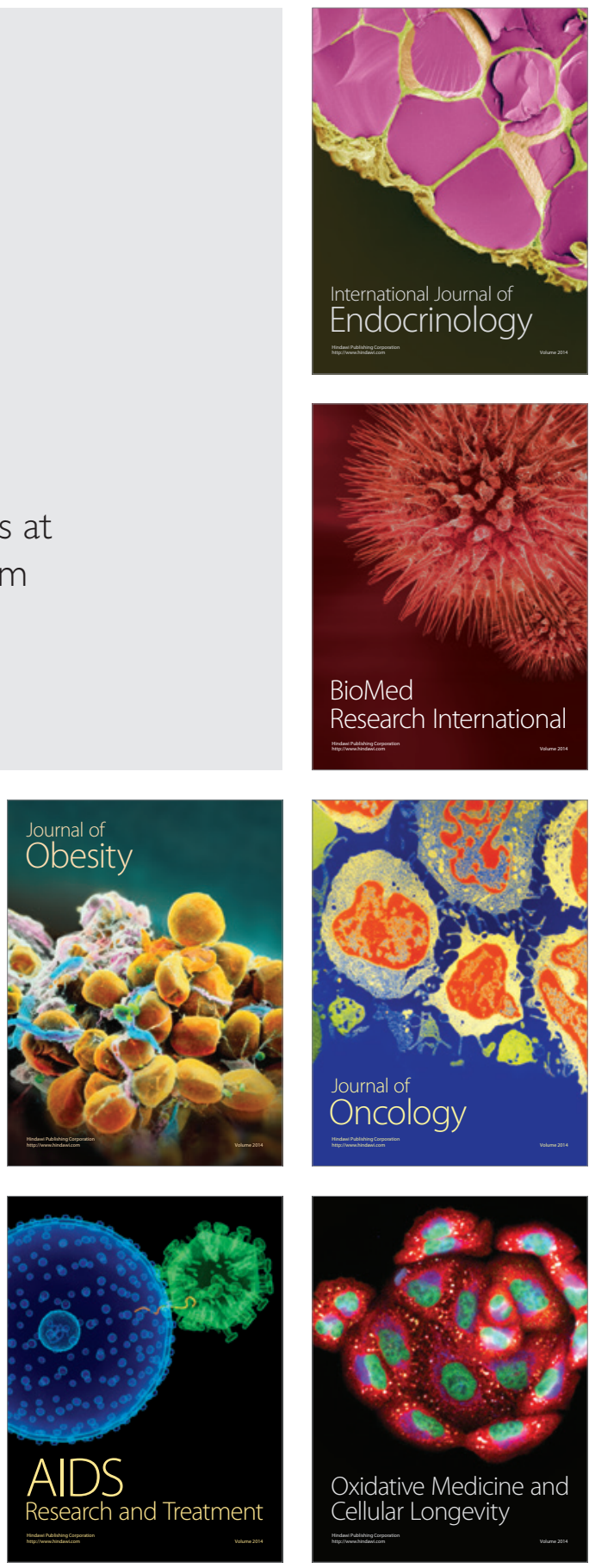